I have thus, in examining the contents of the stomachs of birds from the Sargasso Sea, never found the slightest trace of the characteristic fauna from the Sargassum, and it is therefore possible that it is difficult for the birds to catch the fishes and crabs hiding in these dense masses of drifting sea-weed. Examinations of the stomachs have, on the other hand, always shown that the birds, at least the majority of them, live on flying fishes and cephalopods. This shows that the birds in the Sargasso Sea do not avail themselves of the special Sargassum fauna but seek their food amongst fishes, cephalopods, etc., living free in the water.

It is therefore interesting to study the quantity of macroplankton to be found in the Sargasso Sea and the Gulf Stream respectively. In a previous paper ${ }^{1}$ I have drawn a comparison between the quantity of macroplankton in various parts of the Atlantic, and it appears from this comparison that the quantity of macroplankton in the central parts of the Atlantic between $40^{\circ}$ and $50^{\circ} \mathrm{N}$. lat. is at least ten times as great as that in the Sargasso Sea.

The reason for the scarcity of bird life in the Sargasso Sea, as compared to that in the Gulf Stream area and, on the whole, in the northern Atlantic, may, therefore, safely be sought in the much smaller quantity of food to be found in the Sargasso Sea as compared to the parts of the Atlantic lying farther north.

1 P. Jespersen: On the Quantity of Macroplankton in the Mediterranean and the Atlantic. Rep. on the Danish Oceanogr. Expeditions, I908-10, vol. iii. 3. Copenhagen, I923.

\title{
The Planet Mars.
}

\section{By Dr. W. H. Steavenson.}

THestin HIS year's favourable opposition of Mars, which on August 22 is nearer to the earth than at any time between the eighteenth and twenty-first centuries, would seem a fitting occasion for a brief review of our present knowledge of the planet, together with an estimate of the prospects and probable direction of future research.

The object aimed at in physical observations of Mars may be considered as twofold. First, it is desired to determine, so far as available means will allow, the true appearance of the features presented to our view on the planet's surface ; and, secondly, it is hoped, by careful and repeated observation of these features and the changes that occur in them, to reach some definite conclusions as to their real nature. Both of these objects have been kept in view from the earliest days of the telescope, but it is only in recent years that the second of them has begun to show reasonable prospect of fulfilment. The fact is, of course, that the one object is dependent on the other, so that the first must be attained, approximately at least, before the second can be pursued with any confidence of success. Thus it comes about that the history of Martian observation naturally divides itself into two stages, which we may term respectively that of cartography and that of interpretation. One, of course, is but a development of the other, and there is no sharp dividing line between the two.

From the earliest days of the telescope, it was recognised that the "spots on Mars" were relatively permanent features of the planet's surface, but the first attempts to construct even a rough map of them did not meet with much success. The drawings made by Sir William Herschel late in the eighteenth century are among the first on which we can recognise a number of markings that have since become familiar to us, and it was this great astronomer who, by his study of the polar caps, contributed the first piece of intelligent interpretation of Martian phenomena. But the first map of Mars, properly so called, was not produced until 1840 , when Beer and Mädler gave to the world the results of their systematic work with a refractor of less than four inches aperture. This first map was followed, during the succeeding fifty years, by many others of increasing completeness and accuracy, each being in general the work of a single observer. During this period, thanks largely to the work of Schiaparelli, the areographical positions of the main features were fixed with some approach to finality, and a firm foundation was thus laid for future work. Finally, during the past thirty years or so, progress in cartography has been notably accelerated by the introduction of the co-operative system in observation, as exemplified by the work of such bodies as the British Astronomical Association. Meanwhile, as a result of these advances, we have begun to feel ourselves in a position to attack the problem of rational interpretation, based on the data so far accumulated. Much has, in fact, already been accomplished in this direction, and it is satisfactory to find that the theories are beginning to stand the crucial test of prediction.

To summarise all that is so far known with certainty is not altogether easy, for many of the results of observation, doubtless in most cases quite trustworthy, still lack that general confirmation which would justify us in accepting them with complete confidence. However, the following would probably be accepted on all hands as a fair statement of the present condition of definite knowledge concerning Mars.

(x) The fact of the general permanence of the larger dark markings has been established, and their positions and outlines have been determined with considerable accuracy. In other words, we are in a position to construct a very recognisable map of the planet, as regards its main features.

(2) As a result of the above, it has been possible to ascertain the inclination of the planet's axis within a few minutes of arc, and to determine the rotation period within less than a tenth of a second of time.

(3) The size and rate of diminution of the polar caps has been shown to bear a definite relation to $(a)$ the progress of the Martian seasons, $(b)$ the distance of the planet from the sun, and $(c)$ the extent of solar radiation as indicated by the sun-spot cycle. There is now general agreement that the caps must represent frozen water, the alternative of carbon dioxide, suggested some years ago, being for many reasons untenable.

(4) The large dark markings, while in general permanent in position and outline, are known to 
undergo changes in intensity, both general and local. Some of these changes of intensity are clearly seasonal and regular, while for others no definite period can yet be assigned. They are probably of a secular or irregular nature. Some typical examples are shown in Figs. 2-4. Changes of colour, of seasonal origin, undoubtedly occur, but the regularity of these has not been satisfactorily demonstrated, and all the markings do not appear to share the same changes.

(5) Both dark and light regions of the planet are subject to temporary obscuration by patches of (a) white and (b) yellow material. The former, which occur most frequently near limb or terminator, have been variously ascribed to cloud, fog, snowfalls, or hoar-frost ; the latter to cloud, dust-storms, or blown sand. We are, however, not yet justified in definitely attributing a particular obscuration to any one of these causes, though probably all are in operation at some time or other.

(6) Apart from the larger markings, the existence has been established of an intricate system of finer details, the exact form of which is still uncertain, though there is not the least doubt as to its objectivity.

(7) Finally, satisfactory photographic confirmation has been secured of practically all the above results.

Further elaboration here of all the sections of this summary is not necessary, but special reference should best qualified to judge. In the case of objects which lie so near the limits of visibility, factors of a climatic, instrumental, and personal nature are bound to enter very largely into the matter, and there is consequently room for much difference of opinion. The "canals" having been seen and drawn as fine lines by experienced observers using apertures of 36 and 40 inches under

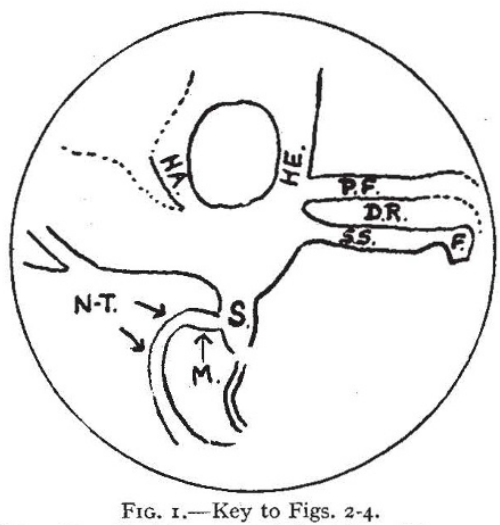
HE. $=$ Hellespontus. $\quad$ S. $=$ Syrtis Major. P.F.= Pandoræ Fretum. $\quad M .=$ Lacus Moeris Fis Regio. $\mathrm{N}-\mathrm{T} .=$ Nepenthes-Thoth
Sinus Furcosus.
HA. $=$ Mare Hadriacum. S.S. $=$ Sinus Sabæus. good climatic conditions, the failure to see them with a somewhat smaller aperture in a less favourable position does not carry an overwhelming amount of weight; and in any event such evidence is purely negative. On the other hand, it does not seem that the linear character of the markings in question has yet been completely demonstrated. No doubt the decision must ultimately come from the large apertures, but it is an unfortunate fact that the ideal combination of a large and perfect instrument, a first-rate climate, and a thoroughly efficient and trustworthy observer, who is also a finished draftsman and entirely free from the bias of preconceived ideas, has never yet been attained. The evidence of photography cannot be regarded as conclusive in either direction, though it has at least proved the objectivity of detail that is approximately linear. Since, however, it is impossible as yet to obtain a distinct photographic image of any features that are beyond the visual reach of an eight-inch tele-

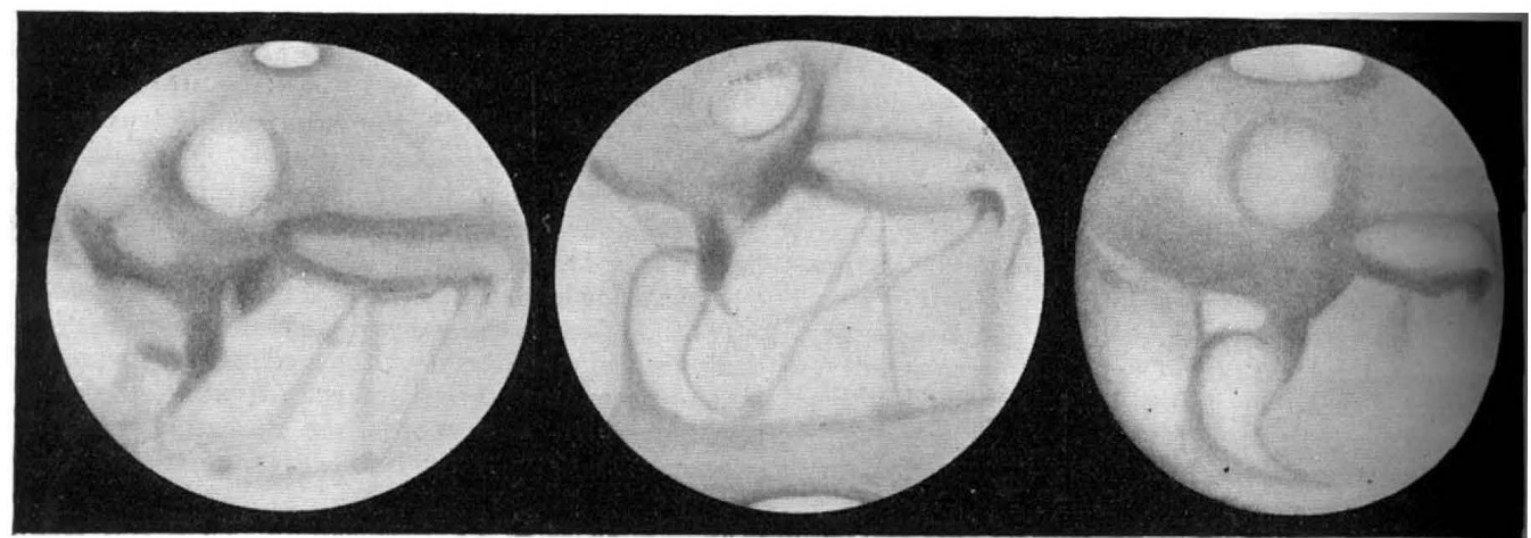

Fig. 2.-Mars. September rgog. Note great development of Lacus Moeris, considerable breadth and intensity of Pandoræ Fretum, and darkness of M. Hadriacum as compared with Hell
of Syrtis Major pointed.
FIG. 3.-Mars. July r922. Lacus Moeris only moderately developed as a mere continuation of Nepenthes-Thoth. Pandoræ Fretum narrow and faint, bein far less prominent than Sinus Sabæus. Sinus very dark. North end of Syrtis Major blunt.
FIG. 4.--Mars. Iuly r924. Lacus Moeris poorly developed. Pandoræ Fretum 6carcely visible as a separate marking. Deucalionis Regio very pale as compared wit area to the south of it. Hellespontus darke Major more pointed than in 1922 be made to the sixth, since under this is included the so-called "canals," which have loomed so large in the more recent history of Martian observation. There seems to be a widespread impression, among those not in direct contact with the subject, that the existence of fine linear markings on Mars has been definitely and finally disproved. Actually, the question still remains entirely open in the opinion of those scope, it follows that a really narrow line, if recorded at all, can only appear as a diffuse marking on the plate, so that we are still left in doubt as to its true structure.

It is, perhaps, unfortunate that so much time and effort has been expended on this difficult question of the finer detail, especially with instruments that are in any event inadequate for a final decision. Observers

NO. 2860 , VOL. I I 4 ] 
are apparently beginning to realise this, and more attention is now being paid, and that more profitably, to the less doubtful subject of changes in the large markings. This work is well within the compass of the instruments generally to be found in the hands of amateurs, who would do well, in the present writer's opinion, to leave the finer details to the larger apertures. In thus getting back to the partially neglected study of the more conspicuous features, we shall be correcting the mistake of attempting to run before we can walk. A good beginning has been made, but it is well to realise that it is no more than a beginning, and it will probably be many years before sufficient data have been accumulated to enable us to judge of the soundness or otherwise of current theories.
In recent years there has been much speculation as to the possible climate and temperature of Mars, and the density and composition of its atmosphere. This sort of thing is apt to blind us to the cold fact that our actual knowledge of these things, if knowledge it can be called, is still exceedingly vague, uncertain, and even contradictory. In view of this, the free and confident use of such definite terms as "cloud," " fog," "hoar-frost," and "vegetation" would seem to be somewhat premature, and liable to check progress by giving rise to a false impression of finality in our deductions. However eager we may be for a quick explanation of observed appearances, we cannot better serve the interests of research than by keeping an open mind.

\section{Obituary.}

Prof. James Seth.

IN Prof. James Seth, who died of failure of the heart 1 on July 24, at the age of sixty-four years, Edinburgh has lost one who belonged to the great race of Scottish professors. Educated at George Watson's College and the University of Edinburgh, he went through a complete course of training for the ministry at the Free Church College. Turning from his original intention to his true vocation, he studied philosophy at Leipzig, Jena, and Berlin. In $\mathrm{I}_{8} 8_{3}$ he became assistant to Prof. Campbell Fraser in his own University, and two years afterwards was appointed professor of philosophy at Dalhousie College, Halifax, Nova Scotia. In I 892 he accepted a chair in Brown University, Providence, Rhode Island, and four years later the Sage professorship of moral philosophy in Cornell University. From Cornell he was recalled in 1898 to succeed Prof. Calderwood in the chair of moral philosophy in Edinburgh.

During his twenty-six years' tenure of this post, Seth made a place for himself in the life of the University and the city that would bear comparison with the most distinguished in the long line of his predecessors. Not so well known as his elder brother and colleague, Andrew Seth Pringle-Pattison, he had the same high standard of scholarship in philosophy and much of the same distinction of style in his written work. The writer of the "appreciation" in the Scotsman on the day after his death, remarked on " the unique partnership so fruitful in good results" between the brothers. For the rest, his methods as a teacher and the place he took in the life of the University and the city were entirely his own. Endowed with great readiness of speech and a singular power of entering into the minds of his students, he was able in spite of the size of his classes to perfect a form of catechetical instruction which was the delight of his students and made "Prof. Jim " for a quarter of a century one of the most popular teachers in Scotland.

On the other hand, related by his subject of moral (which, on his interpretation of it, meant also political) philosophy to the civic life of the community, Seth took the warmest practical interest in all advanced movements. He held that "it is for the State to emancipate from the slavery of social conditions the toiling masses of society, to endow those who are citizens only in name with a real ethical citizenshipthe franchise of a complete and worthy human life," in a word, "to co-ordinate the industrial with the ethical life." It was in such a "regulative socialism " that he found the via media between individualistic and communistic extremes. In the same spirit he interested himself in the Settlement and kindred movements and took a leading part in the establishment of a course of study in social science with the view of linking these more closely with the University. His wide connexion with America and the Continent and his generous hospitality made the bachelor home, which he shared with his younger brother John, a rendezvous of scholars from all parts of the world as well as of his more intimate friends in Britain. It was altogether in harmony with the genius for friendship that was so marked a feature of his character that he died in the course of a round of calls upon acquaintances who were themselves in trouble. Sic vivamus ut sic moriamur.

Seth's chief contributions to philosophy were his book upon "Ethical Principles" (I894), now in its fifteenth edition, and the volume in the series Channels of English Literature on "English Philosophers and Schools of Philosophy" (I912). In the former of these he expounds in a masterly way and with a fine sense of the power of the English language the sober form of idealism with which, by his own teaching not less than that of Campbell Fraser, Simon Laurie, and his brother, philosophy in Edinburgh has been identified. It differs, as the student of philosophy knows, from that associated with the great sister University in the West under the influence of Edward Caird and Henry Jones, chiefly in the emphasis it lays on separate will and personality as an ultimate category and its more definite teaching on the subjects of theism and individual immortality. This is not the place for comparison and criticism, but we touch here on what is probably the main issue between Idealistic philosophers at the present time and we can ill spare the help which so open-minded and "synoptic " a thinker as Prof. Seth might have rendered in clearing it up in the greater leisure of the retirement to which he had been looking forward. We may hope that he has left behind him some record of his maturest thought upon it that may yet be published.

J. H. Muirhead.

NO. 2860 , vOL. I I 4 ] 